\title{
Considerations for classroom seating arrangements and the role of teacher characteristics and beliefs
}

\author{
Mariola C. Gremmen ${ }^{1,2}$ • Yvonne H. M. van den Berg ${ }^{1}$ • \\ Eliane Segers ${ }^{1} \cdot$ Antonius H. N. Cillessen $^{1}$
}

Received: 11 January 2016/Accepted: 3 August 2016/Published online: 2 December 2016

(C) The Author(s) 2016. This article is published with open access at Springerlink.com

\begin{abstract}
As a part of classroom management, teachers face the question of how and where to seat their students. However, it is far from clear what considerations teachers have when making seating arrangements. Therefore, in this study seating arrangement considerations from 50 teachers in grades 4-6 of elementary school were assessed. In Phase 1, teachers were interviewed about their goals and considerations for classroom seating arrangements. Teachers mentioned between 2 and 19 reasons for placing students at specific places in the classroom, with mostly academic considerations. They mainly preferred arrangements in small groups to promote student cooperation. In Phase 2, teachers completed a questionnaire about seating arrangements. This allowed us to examine individual differences between teachers related to gender, years of experience, and beliefs, and the concurrence between the interview and questionnaire data. Teachers reported multiple and various considerations for seating arrangements. Correlations with their general student-oriented or subject-oriented beliefs and personal characteristics were low. The concurrence between measurement methods also was low. The discussion focused on teacher awareness of classroom seating arrangements as an important part of classroom management and a tool for prevention and intervention.
\end{abstract}

Mariola C. Gremmen

m.c.gremmen@rug.nl

Yvonne H. M. van den Berg

y.vandenberg@psych.ru.nl

Eliane Segers

e.segers@pwo.ru.nl

Antonius H. N. Cillessen

a.cillessen@psych.ru.nl

1 Behavioural Science Institute, Radboud University, Montessorilaan 3, 6500 HE Nijmegen, The Netherlands

2 Present Address: Grote Rozenstraat 31, 9712 TG Groningen, The Netherlands 
Keywords Classroom management - Classroom seating arrangements - Teacher considerations - Teacher beliefs

\section{Introduction}

Students spend a large amount of time in a classroom, where desks are arranged in a specific way and individual seats are determined by the teacher. At the beginning of the school year, as part of classroom management, teachers face the question of how and where to seat their students. This is an important decision, as classroom seating arrangements influence classroom climate and students' relationships with each other (van den Berg et al. 2012; Gest and Rodkin 2011; McKeown et al. 2015). In addition, the physical space of the classroom influences learning and impacts teachers' and students' attitudes towards school (Denton 1992). However, it is far from clear what considerations teachers have when making seating arrangements. This insight may help teachers to make (even) more structured and considered decisions, resulting in more effective seating arrangements and less concerns for teachers about how to arrange the classroom in a good way (McKeown et al. 2015). It can also stimulate a better academic and social development for the students (van den Berg et al. 2012; Wannarka and Ruhl 2008). Knowledge about what teachers do and which goals and considerations they have is necessary in order to develop adapted interventions, based on teachers' needs and practices. Therefore, the present study focused on teachers' considerations for classroom seating arrangements and on individual differences between teachers, by using qualitative as well as quantitative methods.

\subsection{Classroom management}

Teachers need to have the ability to educate diverse students within a complicated and challenging classroom context (Sleeter and Owuor 2011). This can be accomplished through effective classroom management, which has been defined as "the actions teachers take to create an environment that supports and facilitates both academic and social-emotional learning" (Evertson and Weinstein 2006, pp. 4-5). It is important for teachers to establish and sustain an orderly environment in the classroom. As part of classroom management, teachers have to make complex decisions on how to establish order, engage students, and elicit their cooperation (Emmer and Stough 2001). Thus, classroom management is related to teachers' decisions and actions with regard to the organization and structure of the classroom, which has to be in line with both teachers' own philosophies and the wider school culture.

However, managing the classroom is a serious challenge for teachers and a major cause of teacher burnout and job dissatisfaction in all countries (Evertson and Weinstein 2006). It has been shown to be the most common concern for teachers and administrators (Sokal et al. 2003). Problems with classroom management are even one of the most important factors influencing teachers' decision to leave the profession in their first years. 
Managing the social dynamics in the classroom may be more difficult in classrooms with a great diversity of students (De Arment et al. 2013; Farmer et al. 2016). First, ethnically diverse classrooms need culturally responsive pedagogy by teachers (McKeown et al. 2015; Stringer et al. 2009). Expectations of appropriate behavior are culturally influenced, so conflicts between teachers and students are likely to occur when they have different cultural backgrounds (Weinstein et al. 2004).

Second, classroom management is more difficult and more crucial in inclusive settings. Recently, an inclusion policy in the Netherlands has been implemented, comprising that more and more students with various disabilities follow regular education instead of special education. Due to these recent changes regarding national and international inclusion policies, teachers have to work with an even more diverse group of children and their classroom management decisions became more important as well as challenging. Students with disabilities often have more social difficulties (Farmer et al. 2016) and teachers need to be adaptive experts by demonstrating the ability to be flexible and innovative in their practices (De Arment et al. 2013). Farmer et al. (2016) concluded that teachers who are routine experts (performing skills in response to familiar settings) need assistance with managing social dynamics to support students who have significant academic and social needs.

\subsection{Managing classroom seatings}

One important aspect of classroom management is the physical design of the classroom. A classroom is an adaptable and often a flexible setting for which teachers make an arrangement for the tables, chairs, and other materials in order to stimulate active involvement in the lessons. Also, teachers decide which location is the best to stimulate an individual student's academic and social development, while encouraging teacher-student interaction, reducing distractions, aggression, and "downtime" (Trussell 2008). Thus, teachers are responsible for making decisions regarding the grouping of students and the resulting nested context within classrooms (Baines et al. 2003). They determine whom students sit close to, whom they are exposed to, and with whom they interact during the school day. Unfortunately, this aspect of classroom management is hardly addressed in teacher trainings, even though the physical design of the classroom has shown to be important for both the academic and social development of students.

With regard to students' academic functioning, a review by Wannarka and Ruhl (2008) showed that seating arrangements can increase on-task behavior and decrease off-task behavior. A seating arrangement in rows compared to groups can instigate such positive academic behaviors (e.g., hand-raising for assistance and complying with requests). Rows can especially support students' on-task behavior during independent work. In contrary, it has been shown that seating arrangements in small groups can facilitate interaction between students due to proximity and close positions between peers. This is for example useful during brainstorming and group assignments. Wannarka and Ruhl (2008) have thus shown that seating arrangements can have consequences for students' academic engagement and 
development. However, the nature of the task and consequently the type of desired behavior dictates the most effective type of seating arrangement.

Classroom seating arrangements are not only important for students' academic development, but also for their social functioning in the classroom (Farmer, Lines, and Hamm 2011; Gest and Rodkin 2011). The teachers can have two roles. On the one hand, they can have an authoritative role, meaning that teachers directly influence social processes through active attempts to manage the social network. On the other hand, they can have a facilitative or indirect role, in which they scaffold students' social opportunities to construct their own roles, affiliative groups, and peer cultures (Gest and Rodkin 2011). This can be achieved through general teaching practices such as seating arrangements (Gest and Rodkin 2011) and the physical space of the classroom (Denton 1992). Teachers determine where students sit during the day and thus which students mostly interact with and influence each other. Interpersonal contact between students due to a low physical distance can positively influence their social perceptions on each other. This is in line with the intergroup contact theory and the contact hypothesis, which state that contact can effectively reduce negative peer perceptions and can increase liking among peers (Allport 1954; Pettigrew 1998). Peer relationships are powerful sources of individual behaviors, so students' positive and negative behaviors in the classroom can be reinforced by peers (Gest and Rodkin 2011).

Recently, van den Berg et al. (2012) rearranged classroom seatings and manipulated the interpersonal distance between students to improve negative social relationships between classmates. They found that a rearrangement of seatings can influence social processes in the classroom. Other researchers also provided empirical support for the idea that seating arrangements influence students' relationships and development (e.g., Blatchford et al. 2005; Kahn and McGaughey 1977; Kutnick and Kington 2005; Wannarka and Ruhl 2008), and that peers influence individual students at the classroom level and in small groups, when students are placed together to solve a problem (Barth, Dunlap, Dane, Lochman, and Wells 2004; Burke and Sass 2013; Webb 1989).

Concluding, classroom management is an important task for teachers and part of this task is their responsibility for the physical design of the classroom. In order to assess whether teachers make effective seating arrangements for students' social and academic development (van den Berg et al. 2012; Wannarka and Ruhl 2008) more information is needed on their practices and reasons behind specific choices. It is not yet clear which types of seating arrangements they prefer, what their considerations and goals are when arranging the classroom, and to what extent the arrangements are in agreement with their needs and beliefs.

\subsection{Types of seating arrangements and teachers' considerations}

There are many ways to arrange a classroom, such as the traditional arrangement in straight rows, an arrangement in small groups, U-shaped seatings, or a classroom with undivided, flexible arrangements. Some of these arrangements are more common than others, such as an arrangement in rows or small groups (McCorskey and McVetta 1978; Wannarka and Ruhl 2008). The type of seating arrangement can 
be chosen with different goals in mind (Fives and Buehl 2008; Gest and Rodkin 2011; Kuzborska 2011). For instance, a seating arrangement in rows may be chosen to improve information dissemination, whereas an arrangement in small groups may be chosen to promote student interactions (McCorskey and McVetta 1978).

However, to our knowledge, only two studies questioned teachers about their specific goals and decisions regarding seating arrangements (Gest and Rodkin 2011; McKeown et al. 2015).

Gest and Rodkin (2011) examined teachers' practices and related them to classroom peer networks. As part of the larger assessments in this study, teachers rated five items regarding their motives behind their classroom seating practices. Teachers' strongest consideration was to separate students with behavior problems, followed by promoting academic diversity and promoting new friendships. The least emphasis was placed on creating academically homogeneous groups or creating groups around existing friendships. Preliminary results also suggested that teachers' considerations can influence students' degree of liking and disliking each other (friendships) (Gest and Rodkin 2011). This study showed that teachers exercise an 'invisible hand' in the classroom through designing the physical order in the classroom, with consequences for the ongoing social processes.

In a study by McKeown et al. (2015), ten teachers completed a questionnaire concerning their seating pattern choices and their motivations for adhering to such plans. The results showed that teachers focused on four aspects while making seating arrangements: the alphabetical order, students' gender, their abilities, or a mixture of two or more of the previous. Although the sample size was small, this study was a first step in exploring teachers' considerations.

However, information is scarce concerning how teachers manage classroom social dynamics through seating arrangements. For instance, little is known about how teachers manage social status patterns (e.g., peer norms) or social affiliation patterns (e.g., friendships) which may affect the social atmosphere of classroom settings (Gest et al. 2014). Teachers vary in the extent to which they identify these social dynamics and these variations in attunement are associated with differences in classroom functioning. To actively manage students' relationships, teachers can use specific strategies or practices. Therefore, more insights are needed into teachers' considerations for placing students at specific places within the classroom (Gest et al. 2014). Teachers can have different seating justifications. For example, teachers have to take into account physical differences among students (e.g., auditory/visual problems, gender and height differences). They can also have, among others, social considerations (e.g., placing friends close to each other or separating them), academic considerations (e.g., placing together students with homogeneous/heterogeneous academic capacities), or focus on peace and order in the group (classroom management). In the present study we aimed to gain more insights into teachers' considerations, using both interviews and questionnaires.

\subsection{Differences among teachers due to teacher characteristics and beliefs}

Despite the fact that there is only little research conducted on seatings as a specific aspect of classroom management, many studies have shown that teachers differ a lot 
in their ideas and practices concerning classroom management in general. Teachers may differ in their considerations based on their own characteristics and beliefs. Teachers' beliefs refer to "a proposition which may be consciously or unconsciously held, is evaluative in that it is accepted as true by the individual, and is therefore imbued with emotive commitment; further, it serves as a guide to thought and behavior" (Borg 2001, p. 186). Also, Borg (2001) indicates that teachers' beliefs are usually used to refer to "teachers' pedagogic beliefs, or those beliefs of relevance to an individual's teaching". The most commonly explored areas are teachers' beliefs about teaching, learning and learners (subject-matter- and studentoriented beliefs).

Teachers' beliefs form a central part of their knowledge through which they perceive, process, and act upon information in the classroom (Fang 1996). Such beliefs can influence teachers' goals, classroom interaction patterns, and ultimately students' behavior and achievements (Kuzborska 2011). As a result, teachers' philosophy, beliefs, conceptualizations of teaching, and teaching methods are associated with their classroom management and choice of a physical organization (Denton 1992; Fives and Buehl 2008; Kuzborska 2011). Differences in teacher beliefs can thus lead to different goals and may therefore explain diverse seating arrangements among teachers. Educational beliefs can be quite diverse and based on philosophical, social or cultural perspectives. In the current study we were specifically interested in teachers' beliefs about learning, which can be more traditional ('transmission teaching') or more constructivist ('process-oriented'). We focus on three aspects that may explain differences among teachers: their studentversus subject-matter-oriented beliefs, their years of experience, and their gender.

First, teachers can be student-oriented or subject-matter-oriented. This distinction refers to different views by teachers of teaching and learning methods. Studentoriented beliefs reflect constructivist theories of knowledge and learning by taking into account differences among students and emphasizing collaboration and individual development of skills and competencies (De Vries et al. 2013). For example, teachers may consider it important to take differences between students in aptitudes and interests into consideration. Subject-matter-oriented beliefs focus on the transmission of knowledge and the role of the teacher as knowledge expert. For instance, a teacher may believe that it is important that only the teacher passes the subject matter on to the students. Student-oriented and subject-matter-oriented beliefs are not necessarily opposing orientations, as teachers may have characteristics from both views (De Vries et al. 2013).

Nevertheless, as it has not been investigated before, it is imaginable that these teacher beliefs are uniquely related to the different kinds of seating arrangements. Based on the definitions of both beliefs, subject-matter-oriented teachers are focused on the transmission of knowledge. As this is one of the main goals of teachers with subject-matter-oriented beliefs, they might as well indicate as one of their major goals to improve academic learning. Also, these teachers might be more inclined to choose a seating arrangement in rows, as this type of arrangement is especially suitable for knowledge dissemination (McCorskey and McVetta 1978). In contrary, teachers who are more student-oriented focus more on cooperation between students. These teachers may be more motivated to improve social contact between 
students. They might indicate more social reasons for their seating arrangement than subject-matter-oriented teachers. Moreover, they may more often choose a seating arrangement in groups, in which student interaction is stimulated (McCorskey and McVetta 1978).

Next, years of experience may also be a teacher characteristic that is associated with their considerations. In a review by Veenman (1984) it was shown that beginning teachers experience lots of stress with managing the classroom (often called a "reality shock" or "transition shock"). In addition, he concluded that a vast majority of beginning teachers had difficulties with control and classroom discipline, and allowed much disorder to go unnoticed. This is in line with findings in other studies, in which it was found that teachers who are more experienced become more controlling than beginning teachers, who focus more on social interaction (Martin et al. 2006; Ünal and Ünal 2012).

These different attitudes might be reflected in teachers' considerations for seating arrangements. As beginning teachers have problems with classroom management, they are sometimes less able to work with speed and flexibility (Ünal and Ünal 2012). Therefore, it might be the case that less experienced teachers focus in their teaching mostly on considerations of classroom management and considerations concerning social processes in the classroom. In contrast, experienced teachers are better able to manage the classroom and to react to unpredictable situations, resulting in more flexible and adaptable behavior (Ünal and Ünal 2012). Due to the ability to manage the classroom setting, experienced teachers have the ability to prioritize tasks. Therefore, they might have more time to focus on the academic part and have more academically and traditionally based reasons for their seating arrangements.

Finally, teachers' gender may influence their decision making. However, previous studies focused mainly on the role of gender differences in students on several outcomes instead of examining the teacher's gender. In a study by Martin et al. (2006), no clear effects of teacher gender were found on their beliefs. As it has hardly been studied and the direct role of the gender of the teacher on his/her decisions has not been explored, it is relevant to examine this with regard to their seating arrangement considerations. As women are found to be more emotional and socially oriented than men (Goldenberg and Roberts 2013), it seems plausible that women have more social considerations for their classroom practices than men.

\subsection{Present study}

Teachers have to make decisions regarding seating arrangements several times during the school year, with potential consequences for the social and academic development of their students (Farmer et al. 2011; Gest and Rodkin 2011; van den Berg et al. 2012). Despite the conclusion from several studies that seating arrangements are important, knowledge regarding teachers' considerations for making them is lacking. Mixed methods are most appropriate in applied settings with the purposes of breadth and depth of understanding someone's motives (Creswell et al. 2003). In this explorative study, teachers' considerations were therefore extensively assessed using in-depth interviews as well as questionnaires. 
Interviewing teachers may lead to more insight into teachers' considerations for specific type of seating arrangements and the placing of students (Gest et al. 2014). This can be supported with more structured questionnaires. The method of assessing information, interviews or questionnaires, can influence outcomes (Hook and Rosenshine 1979). While patterns can be detected by using structured questionnaires, semi-structured interviews can provide more in-depth insight in teachers' thoughts, attitudes, and actions (Harris and Brown 2010). Often, these methods are used to obtain both quantitative data on predefined items as well as qualitative data by asking open-ended questions.

Harris and Brown (2010) compared questionnaires and interviews in educational settings and concluded that it is very challenging to compare them as both have different and complementary strengths and weaknesses. Often, complementary but distinct results arise from semi-structured interviews and questionnaires. For instance, questionnaires may be seen as an objective research tool that can produce generalizable results, whereas interviews provide contexts in which participants can elaborate on their ideas and explain perspectives in their own words. Both methods also have their own disadvantages: questionnaires can have a faulty or biased design and interviews can be interpreted too subjectively (Harris and Brown 2010). It may therefore be useful to use both semi-structured interviews and predefined questionnaires while investigating teachers' considerations. Additive, specific questions were asked in the questionnaires to complement information from the interviews.

The following research questions were addressed:

1. Which types of seating arrangements do teachers use in their classrooms and what are their reasons for these specific types?

2. What are teachers' considerations (i.e., academic, social, physical) for placing students while arranging the classroom?

3. To what extent are the type of seating arrangement and teachers' considerations for placing students associated?

4. To what extent are individual differences between teachers related to their reported considerations regarding the seating arrangement?

It was hypothesized that teachers mainly use seating arrangements in rows or in small groups, with the goal of rows to improve information transmission from teacher to students and the goal of small groups to improve student-student interaction and cooperation (McCorskey and McVetta 1978). While arranging the classroom, it was expected that teachers have considerations based on physical problems, academic and school functioning, classroom management, social relationships in the classroom, and information from previous teachers (Gest and Rodkin 2011). Regarding the third research question, it was expected that teachers with mainly academic considerations used a seating arrangement in rows, while teachers with mainly social considerations used a seating arrangement in small groups (Denton 1992; De Vries et al. 2013; Fives and Buehl 2008; Kuzborska 2011; McCorskey and McVetta 1978). With respect to the final research question, concerning individual differences between teachers, there were three specific 
hypotheses. First, it was hypothesized that more experienced teachers and male teachers have more academically based considerations. Second, it was expected that less experienced teachers and female teachers rely more on social decisions (Martin et al. 2006; Ünal and Ünal 2012; Veenman 1984). Third, we hypothesized that more subject-matter-oriented teachers are primarily motivated by improving academic learning and that more student-oriented teachers prefer to improve social contact among students.

\section{Method}

\subsection{Participants and procedure}

This study was part of a larger study on seating arrangements and peer affiliations. Participants were 50 teachers ( 21 male, 29 female) from 4th, 5th, and 6th grade classrooms (some of these were mixed-grade classrooms, such as 4-5 or 5-6) in regular elementary schools in The Netherlands. They were all Caucasian-White and followed higher vocational education. On average, they worked 3.67 days $(S D=1.14)$ in the classroom they were asked about. The schools were located in middle-class communities in the south-eastern Netherlands.

Schools were recruited with a letter explaining the project and follow-up phone calls. During one session (approximately $30 \mathrm{~min}$ ), teachers were interviewed and afterwards they completed a questionnaire concerning the reasons and goals for their seating arrangements, their general educational goals, and their educational beliefs. Data was collected in the first 2 months after summer vacation (September/ October). All teachers received a small gift in return for their participation.

\subsection{Measures}

\subsubsection{Teachers' considerations for seating arrangements (interview)}

Teachers' considerations regarding their seating arrangements were assessed with a semi-structured interview. First, teachers indicated what type of seating arrangement they currently used (rows, groups, or another arrangement). They also indicated the considerations behind their choice and what type of arrangement they prefer in general. Following these initial questions, more specific information was asked about their decisions for the placement of specific (groups of) students in the current classroom. Teachers were asked to indicate their considerations for specific groups of students, dyads, and individuals (see "Appendix 1").

The interviews were video recorded and later transcribed and coded by three independent coders. A coding scheme with six categories of reasons was used: physical, academic, social, classroom management, personal characteristics, and other. These categories were based on relevant considerations in previous papers (e.g., Gest et al. 2014) and by discussing the categories in a subgroup. Each category was divided into subcategories (see "Appendix 2"), based on examples from the interviews. For instance, social reasons were divided into 'promoting positive 
behavior', 'diminishing negative behavior', and 'other social reasons (not negatively or positively framed)'.

Three coders first independently scored 3 of the 50 teacher interviews (at the subcategory level) and discussed their answers and the coding scheme to resolve unclarities. Following this initial training, the coders independently scored the remaining 47 interviews. An inter-rater reliability analysis using the Kappa statistic was performed to determine consistency between each pair of raters at the category level. Inter-rater reliability ranged from $\kappa=.95-.97(p<.001)$, indicating high agreement between raters (Landis and Koch 1977).

One final set of scores was determined for use in the analyses. Dissimilar answers between coders were inspected and when two of the three observers gave the same code, that code was chosen. Only 2 of the 381 reasons in the 47 interviews were scored differently by all three coders. These codes were discussed and the most fitting one was chosen for the analyses.

\subsubsection{Teachers' considerations for seating arrangements (questionnaire)}

Teachers rated 10 statements about the importance of several predefined considerations when making seating arrangements on a 5-point Likert scale (ranging from ' $-2=$ absolutely not important' to ' $2=$ very important'). Statements were based on a combination of teacher decisions identified by Gest and Rodkin (2011) and Gest et al. (2014). Two statements concerning academic considerations, two concerning social relationships, and one statement regarding classroom management were used from Gest and Rodkin (2011). The other five statements were derived from Gest et al. (2014). To assure the validity of the statements, we used a back translation procedure. The statements measured the following categories: social relationships, academic performance, classroom management, and physical characteristics or impairments. An example is: "How important do you think it is to place students with different academic levels close to one another?" Each item was used separately in further analyses. In addition, teachers were asked to rank order the 10 statements $(1=$ most important, $10=$ least important $)$. Afterwards, the ranks were recoded, with higher numbers indicating higher importance.

\subsubsection{Teachers' goals for seating arrangements (questionnaire)}

Teachers rated 10 statements about the consequences of seating arrangements on a 5 -point Likert scale (ranging from ' $-2=$ absolutely not' to ' $2=$ absolutely'). As there was no existing questionnaire available that measured the consequences of seating arrangements, we have developed our own questionnaire by discussing it with several researchers. We have made statements that refer to the same categories (such as classroom management, academic performance, and social relationships) as used by Gest and Rodkin (2011) and Gest et al. (2014). The statements were items concerning cooperation, friendship, liking, behavior, interaction, and motivation. An example is: "To what extent do you think a seating arrangement contributes to better cooperative and helping behavior between students?" Each item was used separately in further analyses. In addition, teachers were asked to rank order the 10 
statements $(1=$ a seating arrangement contributes the most to this, $10=$ a seating arrangement contributes the least to this). The ranks were recoded afterwards, with higher numbers indicating higher importance.

\subsubsection{Student-oriented beliefs and subject-matter oriented beliefs}

Teachers' student-oriented beliefs ( 7 items) and subject-matter oriented beliefs ( 5 items) were measured using the original Dutch items of a questionnaire by De Vries et al. (2013). Teachers indicated to what extent each item applied to them on a 4-point Likert scale $(1=$ not applicable, $2=$ somewhat applicable, $3=$ fairly applicable, 4 = fully applicable). An example of a student-oriented item was: "In my teaching it is important that students develop skills and competencies". An example of a subject-matter-oriented item was: "In my teaching it is important that I pass on my subject matter to the students". Scores on the seven student-oriented items $(\alpha=.73)$ and the five subject-matter oriented items $(\alpha=.77)$ were averaged and standardized within the sample, with positive scores indicating strong studentoriented or subject-matter-oriented beliefs and negative scores indicating weak student-oriented or subject-matter-oriented beliefs (De Vries et al. 2013).

\section{Results}

\subsection{Types of seating arrangements}

The first research question regarded the types of seating arrangements teachers make in classrooms and their reasons for designing them as such. Many teachers (24; $48 \%$ ) divided their students into small groups in the classroom, several teachers $(20 ; 40 \%)$ chose rows, and other teachers $(6 ; 12 \%)$ used another seating arrangement than groups or rows (see Table 1). The most frequently mentioned reason for small groups was cooperation between students, whereas teachers who chose rows did so to create a quiet atmosphere in which students can work well academically.

When asked about their preferred seating arrangement, 35 teachers (70\%) indicated to prefer small groups, while actually only 24 teachers (48\%) used groups at the beginning of the school year. According to the teachers, this was mainly due to students who were too active or too easily distracted in small groups. Teachers mentioned they start with rows in the beginning of the school year to get students to concentrate and try to work with groups later in the year.

\subsection{Considerations for seating arrangements: interviews}

The second research question regarded teachers' considerations for placing children at specific seats in the classroom. In total, the teachers mentioned 417 reasons during the interviews, ranging from 2 to 19 reasons per teacher. Of all reasons, 68 were physical $(16.3 \%), 54$ were social $(12.9 \%), 129$ were academic $(30.9 \%), 70$ regarded classroom management $(16.8 \%), 38$ regarded personal characteristics 


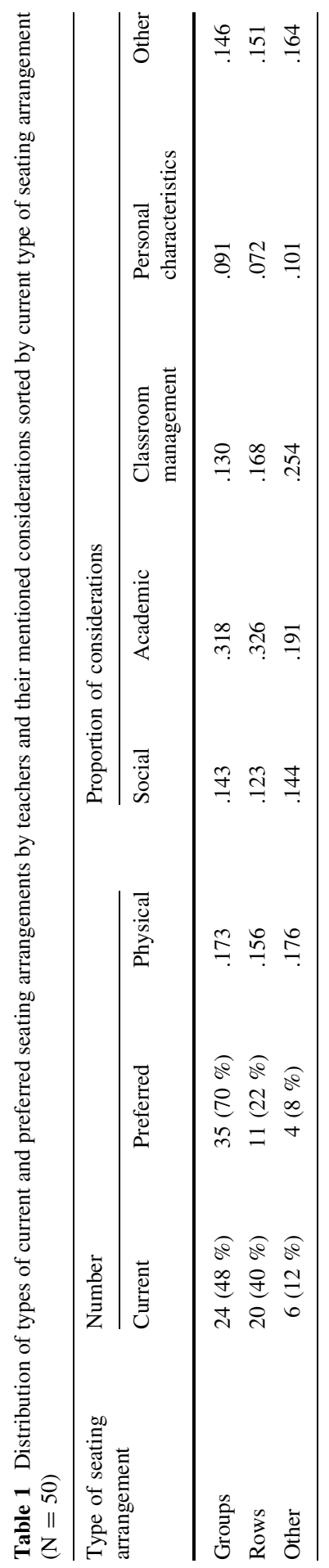


$(9.1 \%)$, and 58 were other reasons $(13.9 \%)$. The other category mostly consisted of reasons concerning a seating arrangement that was preferred by someone else than the teacher (e.g., parents or previous teacher). No category was mentioned by all teachers. When looking at the first reason teachers mentioned during the interviews, the majority of them were academic (30\%).

\subsubsection{Association between teachers' type of seating arrangement and considerations}

We further examined whether there was an association between teachers' type of seating arrangement and their mentioned reasons. Table 1 shows the distribution of considerations by type of current seating arrangement. A one-way ANOVA indicated no significant effect of arrangement type (groups/rows/other) on the category proportions (physical, social, academic, classroom management, personal characteristics, or other). There was no significant difference in mentioned reasons between teachers with different types of seating arrangements.

\subsection{Considerations for seating arrangements: questionnaires}

\subsubsection{Importance of considerations}

Table 2 shows teachers' answers on the questionnaires about the importance of several considerations while making seating arrangements. Significant differences between item means were examined with pairwise comparisons using $t$ tests. The

Table 2 Means and standard deviations of the importance of considerations as indicated by teachers in questionnaires on a scale and with rank ordering $(\mathrm{N}=50)$

\begin{tabular}{lcc}
\hline Items & \multicolumn{1}{l}{ Scale } & Rank order \\
\hline Social & & \\
No friends together & $.38(.97)^{\mathrm{e}}$ & $3.75(2.11)$ \\
Friends together & $-.22(.86)^{\mathrm{f}}$ & $2.75(2.20)$ \\
Academic & & \\
Different academic levels together & $46(1.07)^{\mathrm{f}}$ & $5.36(2.79)$ \\
Same academic levels together & $.04(1.07)^{\mathrm{e}}$ & $3.82(2.52)$ \\
Classroom management & & \\
Students with disruptive behaviour apart & $1.58(.67)^{\mathrm{b}}$ & $7.75(2.05)$ \\
Concentration problems nearby teacher & $1.22(.68)^{\mathrm{c}}$ & $7.39(1.79)$ \\
Motivation problems nearby teacher & $.70(.84)^{\mathrm{d}}$ & $5.59(2.08)$ \\
Learning problems nearby teacher & $.84(.83)^{\mathrm{d}}$ & $6.61(2.23)$ \\
Physical & & \\
Problems: sight and hearing & $1.84(.37)^{\mathrm{a}}$ & $8.16(2.30)$ \\
Differences: e.g. height, left-handed & $.34(1.02)^{\mathrm{e}}$ & $3.84(2.26)$
\end{tabular}

$\overline{\mathrm{a}-\mathrm{f}}$ Significant differences between item means, with ${ }^{\mathrm{a}}$ most important rated item and ${ }^{\mathrm{f}}$ least important rated items 
highest rated item was physical problems: sight and hearing $(M=1.84)$, followed by placing students with disruptive behaviour apart $(M=1.58)$, and placing students with concentration problems nearby the teacher $(M=1.22)$. After these, teachers rated the other classroom management items the highest, followed by one physical and both academic and social reasons. When examining the rank ordering instead of the mean rating, the same sequence of importance of the items was found.

\subsubsection{Contribution of seating arrangements}

In Table 3, teachers' thoughts about the contribution of the seating arrangement to several aspects are shown. Significant differences between item means were examined. The highest rated items were cooperation between students $(M=1.54)$ and creating a positive atmosphere in the classroom $(M=1.44)$, followed by the contribution of a seating arrangement to academic learning from peers $(M=1.34)$. Teachers also thought that seating arrangements can be important to reduce the amount of aggressive and disruptive behavior $(M=1.14)$. The same sequence of importance of the items was found when examining the rank ordering.

\subsection{Individual differences between teachers' considerations}

The fourth research question was whether there are individual differences between teachers that are related to their reported considerations regarding the seating arrangement. These were examined regarding teachers' considerations as mentioned in the interviews and on the questionnaires.

\subsubsection{Interview}

On average, teachers had 16.55 years of experience $(S D=12.17$, range 0-41 years). T-tests indicated that male teachers had more experience than female

Table 3 Means and standard deviations of the contribution of seating arrangements as indicated by teachers in questionnaires on a scale and with rank ordering $(\mathrm{N}=50)$

\begin{tabular}{lcc}
\hline Items & Scale & Rank order \\
\hline Cooperation between students & $1.54(.50)^{\mathrm{a}}$ & $8.04(2.37)$ \\
Students get more friends & $.68(.98)^{\mathrm{c}}$ & $3.77(2.34)$ \\
Students like each other more & $.04(1.03)^{\mathrm{e}}$ & $3.64(2.52)$ \\
Positive atmosphere in the classroom & $1.44(.68)^{\mathrm{a}}$ & $7.94(2.27)$ \\
Less aggressive or disruptive behaviour & $1.14(.88)^{\mathrm{b}}$ & $6.30(2.52)$ \\
Students learn from one another academically & $1.34(.72)^{\mathrm{ab}}$ & $6.68(2.54)$ \\
Diversity in amount of interaction with teacher & $.62(.92)^{\mathrm{c}}$ & $3.19(2.06)$ \\
Diversity in extra instruction by the teacher & $.54(.84)^{\mathrm{cd}}$ & $4.30(2.39)$ \\
Students with motivation problems get motivated by peers & $.90(.71)^{\mathrm{c}}$ & $5.34(2.32)$ \\
Students learn from one another concerning engagement & $1.24(.63)^{\mathrm{b}}$ & $6.38(2.12)$ \\
\hline
\end{tabular}

$\overline{\mathrm{a}-\mathrm{d}}$ Significant differences between item means, with ${ }^{\mathrm{a}}$ most important rated item and ${ }^{\mathrm{d}}$ least important rated item 
teachers, $t(48)=3.226, p=.002, d=1.25$, and that female teachers mentioned more social reasons than male teachers, $t(48)=1.441, p=.027, d=1.18$. There were no other significant associations between teacher gender and seating arrangement considerations. Years of experience was not significantly correlated with teachers' considerations for their seating arrangement.

Teachers indicated equally strong student-oriented beliefs $(M=3.64, S D=.38)$ and subject-matter-oriented beliefs $(M=3.63, S D=.33)$. Teachers who were more student-oriented were also more subject-matter-oriented $(r=.48, p<.001)$. Teachers who had more student-oriented beliefs gave significantly more academic reasons $(r=.31, p=.030)$, more other reasons $(r=.39, p=.006)$, and more total reasons $(r=.45, p<.001)$. Teachers who were more subject-matter-oriented mentioned fewer reasons concerning classroom management $(r=-.28, p=.048)$.

Multiple regression analysis was conducted to investigate whether teachers' considerations per category (physical, social, academic, classroom management, personal characteristics, and other reasons) were predicted by teacher characteristics (Table 4). Gender predicted the number of social reasons $\left(\mathrm{R}_{\text {adjusted }}^{2}=.078\right)$, indicating that female teachers mentioned more social reasons than male teachers. Student-oriented beliefs significantly predicted the number of academic reasons $\left(\mathrm{R}_{\text {adjusted }}^{2}=.027\right)$, reasons concerning classroom management $\left(\mathrm{R}_{\text {adjusted }}^{2}=.136\right)$, and other reasons $\left(\mathrm{R}_{\text {adjusted }}^{2}=.079\right)$. Thus, teachers who indicated high studentoriented beliefs, also gave more academic reasons, reasons concerning classroom management and other reasons. Finally, subject-matter-oriented beliefs only predicted the number of reasons regarding classroom management $\left(\mathrm{R}_{\text {adjusted }}^{2}=.136\right)$. This means that teachers who indicated high subject-matteroriented beliefs gave more reasons regarding classroom management.

\subsubsection{Questionnaire}

$T$ tests indicated no significant differences between the answers of male and female teachers. Pearson correlations $(n=50)$ examined the linear associations between teachers' beliefs, years of experience, and their answers on the questionnaire. There was a negative correlation between years of experience and the belief that seating arrangement contributes to a positive atmosphere in the classroom $(r=-.08, p=.025)$. Thus, younger teachers believed more than older teachers that a seating arrangement contributes to a positive environment for children. Years of experience was not significantly related to the answers regarding the contributions of a seating arrangement or the importance of several reasons. There was also no difference in considerations between more or less student-oriented teachers and subject-matter-oriented teachers.

\section{Discussion}

The goal of this study was to investigate teachers' considerations for designing seating arrangements. Classroom management is a major concern for teachers and teacher educators especially due to cultural and behavioral differences in classrooms 


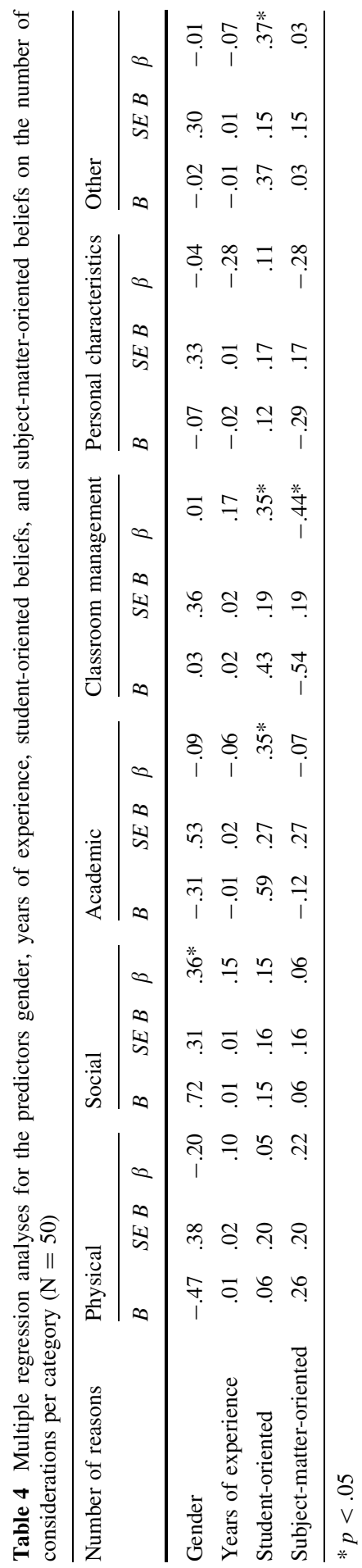


(McKeown et al. 2015; Weinstein et al. 2004). In order to investigate current teacher practices, we explored the types of seating arrangements in this study, as well as teachers' considerations for placing students, and whether teacher characteristics (beliefs, years of experience, and gender) influenced their considerations.

First, the types of seating arrangements and teachers' reasons for choosing them were studied using in-depth interviews. It was hypothesized that teachers mainly use seating arrangements in rows or small groups (McCorskey and McVetta 1978; Wannarka and Ruhl 2008). This was indeed the case. Teachers often start with a seating arrangement in rows at the beginning of the school year to create order and discipline and change it later in the school year into small groups if possible. There was a preference for a seating arrangement in small groups, with the goal of cooperation between students, whereas the main goal of a seating arrangement in rows was to create order and discipline. These results indicate that current teachers try to let students cooperate by sitting in small groups, but are sometimes hindered in doing this due to disorder and/or lack of discipline in the classroom. A quiet atmosphere can be realized more easily with a seating arrangement in rows.

Next, teachers' considerations for placing students while arranging the classroom were examined. It was expected that teachers have considerations based on physical problems, academic and school functioning, classroom management, social relationships in the classroom, and information from previous teachers (Gest and Rodkin 2011). Teachers' considerations as indicated during the interviews could be divided into six categories: physical considerations, social considerations, academic considerations, considerations concerning classroom management, considerations about personal characteristics, and other considerations (such as wishes by students), which is in line with the expected categories. Academic considerations were mentioned the most in interviews. When only examining the first given consideration, academic reasons were also mentioned the most. This implies that academic performance is teachers' most important consideration.

However, in questionnaires physical considerations and considerations concerning classroom management were rated the highest. Classroom management also has been found in previous questionnaire studies as being one of the main considerations for teachers (Gest and Rodkin 2011; Gest et al. 2014). Thus, teachers provided different answers during interviews and on questionnaires. While provided with open-ended questions, teachers were inclined to mostly mention academic reasons for their seating arrangements, whereas in the questionnaires in which all categories were provided, teachers were more inclined to rate different categories as more important. However, imperfect correspondence between teachers' answers to interviews and the questionnaires was expected, as previous studies found complementary but distinct results by using interviews and questionnaires (Hook and Rosenshine 1979; Harris and Brown 2010). The present findings confirm this hypothesis, as teachers who mentioned more social considerations during the interview or had a higher proportion of social considerations did not give higher ratings on the social items of the questionnaires $(r=.05, p=.730)$. This was also the case for academic considerations $(r=.15, p=.290)$. The explanation for this might be that teachers find it difficult to think about all their decisions during interviews (Harris and Brown 2010; Hook and Rosenshine 1979) and there is a large 
difference in the number of mentioned considerations between teachers. Some teachers talked more easily and as a result mentioned more reasons. On top of that, schools are traditionally meant for academic learning, which may press teachers to give many academic considerations (social desirability).

The third research question examined the association between the type of seating arrangement and teachers' considerations. We hypothesized that teachers with mainly academic considerations preferred a seating arrangement in rows, whereas teachers with mainly social considerations preferred small groups (Denton 1992; De Vries et al. 2013; Fives and Buehl 2008; Kuzborska 2011; McCorskey and McVetta 1978). Results showed no association between teachers' considerations and type of seating arrangement. This might be due to the large number of academic considerations for all teachers and the fact that all teachers had very similar proportions of academic and social considerations. It was therefore not possible to clearly distinguish more socially and more academically oriented teachers.

The fourth and final research question concerned the association between teachers' characteristics and their considerations. Results showed that female teachers mentioned significantly more social considerations than male teachers, which is in line with the hypothesis. It might thus be the case that students in classrooms with female teachers sit closer to friends or further away from friends than students with male teachers. As a result, students' social relationships can develop differently. Based on findings by Martin et al. (2006), we also hypothesized that less experienced teachers have more social considerations, whereas more experienced teachers are more academically oriented. Ünal and Ünal (2012) concluded that novice elementary school teachers mainly focused on social interaction whereas experienced teachers mainly wanted to have control. We found no differences in considerations between teachers with different years of experience, but it was measured as a continuous variable and no categories were made with this construct. Teachers varied in years of experience, but the results may be influenced by the fact that the sample size was relatively small (50 teachers).

It was further hypothesized that more subject-matter oriented teachers have more academic considerations and that more student-oriented teachers have more social considerations, based on the distinction between these two beliefs (De Vries et al. 2013). Results showed a significant influence of student-oriented beliefs on the number of academic reasons, reasons concerning classroom management, and other reasons. Subject-matter-oriented beliefs predicted the number of reasons regarding classroom management as well. This is in contrast to the hypotheses, but can be a consequence of the high scores on subject-matter-oriented and student-oriented beliefs and the fact that most teachers scored equally high on both beliefs. Most teachers had rated all studentoriented items and all subject-matter-oriented items as very important.

\section{Limitations and future directions}

The findings of this study add to current knowledge on classroom management in general, and in particular on types of seating arrangements and teachers' considerations for making them. But some limitations apply to the study and should be taken into account in future studies. 
Results showed that teachers mainly chose seating arrangements in rows or small groups. But mixed results were found for teachers' considerations in the interviews and questionnaire data. Results thus depend on the way of gathering them, which should be taken into account in studies assessing teachers' considerations. On top of that, an important finding was that teachers have considerations that fall in different categories and that depend on the situation and the specific students. It will be important in future research to take into account the study objectives to weigh the strengths and limitations of different assessment methods. Still, rather than selecting one method (questionnaire or interview), future work may find multi-method assessments optimal, as they offer a more comprehensive view of teachers' considerations for their seating arrangements.

It is also interesting for future research to examine what teachers are really doing in addition to their self-mentioned considerations. A limitation of the current study was that we did not measure whether the seating arrangement teachers made with several considerations in mind corresponds with students' actual social and academic behavior. Some teachers, for example, wanted to stimulate friendships by putting friends closely to one another, but we did not test whether (reciprocal) friends were actually sitting closely to each other. Another example is that some teachers found academically homogenous groups important, but we did not examine whether students within groups were indeed similar regarding academic performance.

However, researchers should keep in mind that considerations are difficult to measure. This study indicated that teachers have many considerations, also for specific groups of students. Both interviews and questionnaires can provide interesting insights into teachers' thoughts and complement each other in giving a clear overview. Although no differences in considerations due to teachers' characteristics were found, in depth-interviews led to interesting insights. A limitation of the current study was that only fifty teachers participated, which is not ideal for comparing groups on different answers on questionnaires. Therefore, we recommend researchers to replicate and extend the current study by including more participants.

For future research, it would also be interesting to study whether teachers' considerations vary across year grade and across familiarity with the students. The year grade might influence teachers' considerations. For example, it could be that academic reasons become more important in the sixth grade compared to the fourth and fifth grade, as that is the final year in elementary school. In that year, students' academic achievement will be used for deciding which academic level of secondary school to attend. Also, it might be interesting for future studies to take into account for how long teachers already know their students, as that might influence their strategies. For example, it might be the case that teachers base seatings more on personal characteristics of students when they know their students better.

An interesting finding was that female teachers gave more social reasons than male teachers, so there might be a difference in mindset between them. The consequences of these differences can be studied in future studies to see whether especially social processes in the classrooms depend on the teacher's gender. Next to this, teachers reported to be both student-oriented and subject-matter-oriented and 
not having only one of those beliefs the most, which needs to be kept in mind in future studies. These beliefs seem to be complementary and should be used as such. As all teachers rated all statements highly, this questionnaire was not able to create meaningful variations between teachers. A limitation of this study was that other characteristics that were tested in previous studies could not be taken into account as well, such as the teachers' age, personality, or levels of stress (Fontana and Abouserie 1993; Wayne and Youngs 2003). Other teacher characteristics also could have been included, such as the frequency with which the teacher makes a new classroom seating arrangement and how much time she or he invests in it.

The data of the present study have thus shown that teachers differ in their strategies and opinions concerning classroom management and seating arrangements. However, the current questionnaire on student-oriented and subject-matteroriented beliefs was not able to explain these differences. Therefore, we cannot conclude that differences among teachers are due to different teaching beliefs. Nevertheless, other teacher characteristics might explain different strategies among teachers. In future studies, it might also be useful to take a wider contextual approach, by examining the broader school culture, cultural differences between students and teachers, and the role of specific policies (e.g., the inclusion policy).

Moreover, a needed area of research at elementary level is teachers' sense (selfefficacy) of actually being able to manage both classroom and peer relations, and their self-efficacy for classroom management. Ryan et al. (2015) found that teachers feel less efficacious about managing peer relations as compared to classroom management. This calls for more attention to the role of teachers in shaping students' peer experiences and their responsiveness to the social dynamics of the classroom as a whole. This is in line with the idea of 'the invisible hand' (Farmer et al. 2011), which indicates that teacher practices with regard to classroom behavior and general social dynamics are not well understood and rarely studied yet. Also, it relates to the idea that teachers have facilitative roles, next to authoritative roles (Gest and Rodkin 2011; Gest et al. 2014). The SEALS research program (Supporting Early Adolescent Learning and Social Success) is a good example of an intervention that can enhance teachers' capacities to manage social dynamics in the classroom and can promote supportive school environments (Farmer et al. 2013).

A final limitation of this study might be that we have chosen to differentiate between academic and social reasons. Teachers had to rate the importance of specific reasons and they also ordered their importance. Still, a combination of these categories is also possible. We consider academic and social reasons as different constructs as has been done in many previous studies (e.g., Farmer et al. 2011; Gest and Rodkin 2011; Wannarka and Ruhl 2008). However, we know from the literature that these constructs can interact as well. Ladd et al. (2012) indicate that students' social behavior in classrooms and their relationships with peers have an effect on their learning and achievement in schools. Peer relations, such as friendships and working together, can provide a context for academic stimulation. It might thus be possible that teachers emphasize social aspects, such as collaboration, in order to enhance students' academic achievement. 


\section{Conclusions and implications}

Teachers seem to have multiple and various considerations for their seating arrangements, which cannot be simplified into one core theme like 'academic functioning'. The considerations refer to several categories, such as classroom management, social reasons, or physical reasons. In addition, teachers' reasons seem neither related to their visions on academic and social functioning, nor to their personal characteristics, such as gender and years of experience. However, it is remarkable that large differences are found in teachers' reports when they are being interviewed compared to when they report their considerations with predefined response options.

These results can be used in teacher training, by paying more attention to the physical structure of classrooms as part of classroom management. Beginning teachers are often unprepared when they start working. They do not know what to do, which leads to stress. In a recent study it was found that beginning teachers can already benefit from a classroom management training of two and a half days (Dicke et al. 2015). Following such a training, teachers indicated to have higher classroom management skills and to experience less emotional exhaustion and fewer ruminative thoughts. Including more information concerning seating arrangements can strengthen teachers even more.

Moreover, using more well-considered seating arrangements can improve students behavior and learning. It can thus be concluded that teachers need to become more conscious about seating arrangements as an important part of classroom management. Teachers need to be informed about the possibly preventive and intervening effects of a seating arrangement on students' academic and social behaviors. It can be a helpful tool for teachers, who have the difficult task to place all students in the classroom. In addition, it can help teachers in achieving the goals they have to achieve within their education nowadays. Recently, the Dutch ministry has put emphasis on 'social safety' of students as one of the main tasks of schools and teachers, and classroom management as a tool to guarantee this social safety.

In addition, as part of a new policy, students with special educational needs go to regular education as much as possible for social justice and equity reasons. This implies that teachers have more diverse children in the classroom. Next to cultural differences among students, academic and social differences among students enlarge as well. Teachers need to integrate all students in the classroom, which results in even more complicated decisions regarding the physical design of the classroom. They have to think about how students with social-emotional problems become part of the group like everybody else. Is it the best way to place students with education needs in front of the teacher so that they can be helped easily? But how does that relate to their social development? And is it effective to put students' with the same or opposing characteristics close to one another? Many questions arise, which are related to difficult decisions for teachers.

These decisions regarding seating arrangements are less difficult when teachers are attuned to a classroom's social dynamics. Teacher attunement has increasingly been found to be important for positive classroom processes and peer environments (Norwalk et al. 2015; Troop-Gordon 2015). When teachers are attuned well and are 
thus aware of the social structures in their classroom, they are better able to adapt their practices accordingly (Hamm et al. 2011). By making seating arrangements, teachers have a direct possibility to actively manage the classroom, for example by creating opportunities to foster friendships and to reduce aggressive behaviors.

In conclusion, the current study focused on a specific aspect of classroom management, that is classroom seating arrangements. The findings contribute to a relatively new line of research on the importance of the physical structure of classrooms for students' academic and social functioning (Gest and Rodkin 2011; van den Berg et al. 2012). More research should be conducted to replicate and extend current findings on teachers' considerations regarding seating arrangements and to develop adapted interventions. This can provide teachers with valuable knowledge and tools for effective classroom management that may eventually promote students' academic and social development.

Acknowledgments We gratefully acknowledge the contribution of all schools, teachers, and students who participated in this study. Their cooperation and efforts made this project possible.

Open Access This article is distributed under the terms of the Creative Commons Attribution 4.0 International License (http://creativecommons.org/licenses/by/4.0/), which permits unrestricted use, distribution, and reproduction in any medium, provided you give appropriate credit to the original author(s) and the source, provide a link to the Creative Commons license, and indicate if changes were made.

\section{Appendix 1}

Semi-structured interview with teachers

1. I see that you chose for an arrangement in .... (groups/rows/other). Why did you choose this type of arrangement?

- If it is an arrangement in groups: Have you ever thought about an arrangement with students sitting in rows?

Answer no: Why do you not prefer an arrangement in rows?

Answer yes: Why did you not choose for this type of arrangement?

- If it is an arrangement in rows: Have you ever thought about an arrangement with students sitting in groups?

Answer no: Why do you not prefer an arrangement in groups?

Answer yes: Why did you not choose for this type of arrangement?

- If it is another type of arrangement: Have you ever thought about an arrangement with students sitting in groups or rows?

Answer no: Why do you not prefer an arrangement in groups or rows?

Answer yes: Why did you not choose for one of these types of arrangement?

2. What type of seating arrangement do you prefer? Why?

3. Are some students sitting in a certain position for specific reasons?

- If yes: Which students? Why? 
4. What do you take into account while making a seating arrangement?

5. Per group/dyad in the rows/close sitting students in another seating arrangement: Why do these students sit close to one another?

\section{Appendix 2}

Coding scheme of teachers' considerations in categories and subcategories

\begin{tabular}{|c|c|c|}
\hline Category & Subcategory & Example \\
\hline \multirow[t]{4}{*}{ 1. Physical } & 1.1 Auditory/visual & Bad vision/bad hearing by a student \\
\hline & 1.2 Gender & Boys/girls close to one another or separated \\
\hline & 1.3 Height & $\begin{array}{l}\text { Small/tall students; All students can see } \\
\text { blackboard }\end{array}$ \\
\hline & 1.4 Other & Other physical reasons (i.e. left/right handed) \\
\hline \multirow[t]{3}{*}{ 2. Social } & 2.1 Promoting positive behavior & Making new contacts; safety of a friend \\
\hline & 2.2 Diminishing negative behavior & $\begin{array}{l}\text { Friends separated; students who do not like one } \\
\text { another separate }\end{array}$ \\
\hline & $\begin{array}{l}2.3 \text { Other (social; not negative or } \\
\text { positive) }\end{array}$ & Social contacts; friends \\
\hline \multirow[t]{3}{*}{ 3. Academic } & 3.1 Working attitude & Good cooperation, concentration, motivation \\
\hline & 3.2 Academic capacities & $\begin{array}{l}\text { Homogeneous/heterogeneous; instruction } \\
\text { groups; low ability students with high ability }\end{array}$ \\
\hline & 3.3 Other & Cognitive reasons \\
\hline \multirow[t]{3}{*}{$\begin{array}{l}\text { 4. Classroom } \\
\text { management }\end{array}$} & 4.1 Peace and order & $\begin{array}{l}\text { Order in the group, separating disturbing } \\
\text { students? }\end{array}$ \\
\hline & 4.2 Distance to teacher & Learning in sight or not in sight of teacher \\
\hline & 4.3 Other & Separating years or groups \\
\hline \multirow{3}{*}{$\begin{array}{l}\text { 5. Personal } \\
\text { characteristics }\end{array}$} & 5.1 Diagnose & ADHD, autism, PDD-NOS, dyslexia etc. \\
\hline & 5.2 Characteristics & Unsureness, modest \\
\hline & 5.3 Other & Other personal characteristics \\
\hline \multirow[t]{3}{*}{ 6. Other } & $\begin{array}{l}\text { 6.1 Wishes/advices of others } \\
\text { (previous teacher/parents/ } \\
\text { students) }\end{array}$ & Request by students \\
\hline & 6.2 Tools & Social questions \\
\hline & 6.3 Vague descriptions & Variation among students \\
\hline
\end{tabular}

\section{References}

Allport, G. A. (1954). The nature of prejudice. New York: Addison-Wesley.

Baines, E., Blatchford, P., \& Kutnick, P. (2003). Changes in grouping practices over primary and secondary school. International Journal of Educational Research, 39, 9-34. doi:10.1016/S08830355(03)00071-5.

Barth, J. M., Dunlap, S. T., Dane, H., Lochman, J. E., \& Wells, K. C. (2004). Classroom environment influences on aggression, peer relations, and academic focus. Journal of School Psychology, 42, 115-133. doi:10.1016/j.jsp.2003.11.004. 
Blatchford, P., Galton, M., Kutnick, P., \& Baines, E. (2005). Improving the effectiveness of pupil groups in classrooms. Final report to ESRC (L139 25 1046).

Borg, M. (2001). Teachers' beliefs. ELT Journal, 55, 186-188.

Burke, M. A., \& Sass, T. R. (2013). Classroom peer effects and student achievement. Journal of Labor Economics, 31, 51-82. doi:10.1086/666653.

Creswell, J. W., Plano Clark, V. L., Gutmann, M. L., \& Hanson, W. E. (2003). Advanced mixed methods research designs. In A. Tashakkori \& C. Teddlie (Eds.), Handbook of mixed methods in social and behavioral research (pp. 209-240). Thousand Oaks, CA: Sage.

De Arment, S. T., Reed, E., \& Wetzel, A. P. (2013). Promoting adaptive expertise: A conceptual framework for special educator preparation. Teacher Education and Special Education, 36, 217-230. doi:10.1177/0888406413489578.

de Vries, S., van de Grift, W. J., \& Jansen, E. P. (2013). Teachers' beliefs and continuing development. Journal of Educational Administration, 51, 213-231. doi:10.1108/09578231311304715.

Denton, P. (1992). Seating arrangements for better classroom management. Adventist Education, 54(5), 29-32.

Dicke, T., Elling, J., Schmeck, A., \& Leutner, D. (2015). Reducing reality shock: The effects of classroom management skills training on beginning teachers. Teaching and Teacher Education, 48, 1-12.

Emmer, E. T., \& Stough, L. M. (2001). Classroom management: A critical part of educational psychology, with implications for teacher education. Educational Psychologist, 36(2), 103-112. doi:10.1207/S15326985EP3602_5.

Evertson, C. M., \& Weinstein, C. S. (Eds.). (2006). Handbook of classroom management: Research, practice, and contemporary issues. Mahwah, NJ: Erlbaum.

Fang, Z. (1996). A review of research on teacher beliefs and practices. Educational Research, 38, 47-65. doi:10.1080/0013188960380104.

Farmer, T. W., Chen, C.-C., Hamm, J. V., Moates, M. M., Mehtaji, M., Lee, D., et al. (2016). Supporting teachers' management of middle school social dynamics: The scouting report process. Intervention in School and Clinic. doi:10.1177/1053451216636073.

Farmer, T. W., Hamm, J. V., Lane, K. L., Lee, D., Sutherland, K. S., Hall, C. M., et al. (2013). Conceptual foundations and components of a contextual intervention to promote student engagement during early adolescence: The Supporting Early Adolescent Learning and Social Success (SEALS) Model. Journal of Educational and Psychological Consultation, 23(2), 115-139. doi:10.1080/10474412. 2013.785181.

Farmer, T. W., Lines, M. M., \& Hamm, J. V. (2011). Revealing the invisible hand: The role of teachers in children's peer experiences. Journal of Applied Developmental Psychology, 32, 247-256. doi:10. 1016/j.appdev.2011.04.006.

Fives, H., \& Buehl, M. M. (2008). What do teachers believe? Developing a framework for examining beliefs about teachers' knowledge and ability. Contemporary Educational Psychology, 33, 134-176. doi:10.1016/j.cedpsych.2008.01.001.

Fontana, D., \& Abouserie, R. (1993). Stress levels, gender and personality factors in teachers. British Journal of Educational Psychology, 63, 261-270. doi:10.1111/j.2044-8279.1993.tb01056.x.

Gest, S. D., Madill, R. A., Zadzora, K. M., Miller, A. M., \& Rodkin, P. C. (2014). Teacher management of elementary classroom social dynamics: Associations with changes in student adjustment. Journal of Emotional and Behavioral Disorders, 22, 1-12. doi:10.177/1063426613512677.

Gest, S. D., \& Rodkin, P. C. (2011). Teaching practices and elementary classroom peer ecologies. Journal of Applied Developmental Psychology, 32, 288-296. doi:10.1016/j.appdev.2011.02.004.

Goldenberg, J. L., \& Roberts, T. A. (2013). The beast within the beauty. In J. Greenberg (Ed.), Handbook of Experimental Existential Psychology (pp. 71-75). New York: Guilford Press.

Hamm, J. V., Farmer, T. W., Dadisman, K., Gravelle, M., \& Murray, A. R. (2011). Teachers' attunement to students' peer group affiliations as a source of improved student experiences of the school socialaffective context following the middle school transition. Journal of Applied Developmental Psychology, 32(5), 267-277. doi:10.1016/j.appdev.2010.06.003.

Harris, L. R., \& Brown, G. T. L. (2010). Mixing interview and questionnaire methods: Practical problems in aligning data. Practical Assessment Research \& Evaluation, 15, 1-19.

Hook, C. M., \& Rosenshine, B. V. (1979). Accuracy of teacher reports of their classroom behavior. Review of Educational Research, 49, 1-11. doi:10.3102/00346543049001001.

Kahn, A., \& McGaughey, T. A. (1977). Distance and liking: When moving close produces increased liking. Sociometry, 40, 138-144. doi:10.1080/01411920120122149. 
Kutnick, P., \& Kington, A. (2005). Children's friendships and learning in school: Cognitive enhancement through social interaction? British Journal of Educational Psychology, 75, 521-538. doi:10.1348/ $000709904 X 24591$.

Kuzborska, I. (2011). Links between teachers' beliefs and practices and research on reading. Reading in a Foreign Language, 23, 102-128.

Ladd, G. W., Kochenderfer-Ladd, B., Visconti, K. J., \& Ettekal, I. (2012). Classroom peer relations and children's social and scholastic development: Risk factors and resources. In A. M. Ryan \& G. W. Ladd (Eds.), Peer relations and adjustment to school (pp. 11-50). Charlotte, NC: Information Age.

Landis, J. R., \& Koch, G. G. (1977). The measurement of observer agreement for categorical data. Biometrics, 33, 159-174. doi:10.2307/2529310.

Martin, N. K., Yin, Z., \& Mayall, H. (2006). Classroom management training, teaching experience and gender: Do these variables impact teachers' attitudes and beliefs toward classroom management style? Paper presented at the annual conference of the Southwest Educational Research Association, Austin, TX.

McCorskey, J. C., \& McVetta, R. W. (1978). Classroom seating arrangements: Instructional communication theory versus student preferences. Communication Education, 27, 99-111. doi:10. 1080/03634527809378281.

McKeown, S., Stringer, M., \& Cairns, E. (2015). Classroom segregation: Where do students sit and how is this related to group relations? British Educational Research Journal, 42(1), 40-55. doi:10.1002/ berj. 3200 .

Norwalk, K. E., Hamm, J. V., Farmer, T. W., \& Barnes, K. L. (2015). Improving the school context of early adolescence through teacher attunement to victimization effects on school belonging. Journal of Early Adolescence. doi:10.1177/0272431615590230.

Pettigrew, T. F. (1998). Intergroup contact theory. Annual Review of Psychology, 49, 65-85.

Ryan, A. M., Kuusinen, C. M., \& Bedoya-Skoog, A. (2015). Managing peer relations: A dimension of teacher self-efficacy that varies between elementary and middle school teachers and is associated with observed classroom quality. Contemporary Educational Psychology, 41, 147-156.

Sleeter, C. E., \& Owuor, J. (2011). Research on the impact of teacher preparation to teach diverse students: The research we have and the research we need. Action in Teacher Education, 33, 524-536. doi:10.1080/01626620.2011.627045.

Sokal, L., Smith, D. G., \& Mowat, H. (2003). Alternative certification teachers' attitudes toward classroom management. The High School Journal, 86, 8-16.

Stringer, M., Irwing, P., Giles, M., McClenahan, C., Wilson, R., \& Hunter, J. A. (2009). Intergroup contact, friendship quality and political attitudes in integrated and segregated schools in Northern Ireland. British Journal of Educational Psychology, 79(2), 239-257. doi:10.1348/978185408X368878.

Troop-Gordon, W. (2015). The role of the classroom teacher in the lives of children victimized by peers. Child Development Perspectives, 9(1), 55-60. doi:10.1111/cdep.12106.

Trussell, R. P. (2008). Classroom universals to prevent problem behaviors. Intervention in School and Clinic, 43, 179-185. doi:10.1177/1053451207311678.

Ünal, Z., \& Ünal, A. (2012). The impact of years of teaching experience on the classroom management approaches of elementary school teachers. International Journal of Instruction, 5, 41-60.

van den Berg, Y. H. M., Segers, E., \& Cillessen, A. H. N. (2012). Changing peer perceptions and victimization through classroom arrangements: A field experiment. Journal Abnormal Child Psychology, 40, 403-412. doi:10.1007/s10802-011-9567-6.

Veenman, S. (1984). Perceived problems of beginning teachers. Review of Educational Research, 52, $143-178$.

Wannarka, R., \& Ruhl, K. (2008). Seating arrangements that promote positive academic and behavioral outcomes: A review of empirical research. Support for Learning, 23, 89-93. doi:10.1111/j.14679604.2008.00375.x.

Wayne, A. J., \& Youngs, P. (2003). Teacher characteristics and student achievement gains: A review. Review of Educational research, 73, 89-122. doi:10.3102/00346543073001089.

Webb, N. (1989). Peer interaction and learning in small groups. Journal of Educational Research, 13, 21-39. doi:10.1111/j.1467-9604.2008.00375.x.

Weinstein, C. S., Tomlinson-Clarke, S., \& Curran, M. (2004). Toward a conception of culturally responsive classroom management. Journal of Teacher Education, 55, 25-38. doi:10.1177/ 0022487103259812. 
Mariola C. Gremmen is Ph.D. student in the Inter-university Center for Social Science Theory and Methodology (ICS) at the University of Groningen, The Netherlands. Her research interests include the development of children's and adolescents' social networks and their academic achievement.

Yvonne H. M. van den Berg is assistant professor of developmental psychology in the Behavioural Science Institute at Radboud University, Nijmegen, The Netherlands. Her research interests include child and adolescent peer relationships and peer group dynamics in classrooms and schools.

Eliane Segers is associate professor in the Behavioural Science Institute (BSI) at Radboud University, Nijmegen, The Netherlands. Her research focuses on individual variation in learning and learning problems, with an additional interest in dyadic learning and on the social context of the classroom.

Antonius H. N. Cillessen is professor of developmental psychology and quantitative methods and director of the Behavioural Science Institute (BSI) at Radboud University, Nijmegen, The Netherlands. His research interests include child and adolescent peer relationships and quantitative methods for developmental research. 